\title{
Políticas de seguridad y migración del Estado mexicano: Impacto en derechos humanos de migrantes y sus defensores
}

\author{
José Ascención Moreno Mena ${ }^{1}$, \\ Lya Margarita Niño Contreras ${ }^{2}$
}

\author{
Categoría: Comunicado \\ Fecha de recepción: 28 de mayo de 2012 \\ Fecha de aprobación: 11 de julio de 2012
}

\begin{abstract}
Resumen
Se explora el impacto de las políticas de migración y seguridad implementadas por el Estado mexicano en los derechos humanos de los migrantes y sus defensores. Nos apoyamos en información arrojada en ejercicios de grupos focales con miembros de las Organizaciones Civiles (OC) en los años 2010 y 2011, en documentos elaborados por ellos mismos, así como en entrevistas a sus líderes más representativos. Encontramos que en la estrategia de seguridad del gobierno ha estado ausente un enfoque de seguridad humana, esa carencia ha permitido la proliferación de distintas violaciones a los derechos humanos así como la criminalización de los migrantes y sus defensores. De igual forma se detectó la existencia de fisuras que obstaculizan el desempeño de las políticas mencionadas; así como la proliferación de actores que acentúan la vulnerabilidad de los sujetos en cuestión, al menos 63 defensores de derechos humanos han sido asesinados, otros 158 están bajo medidas cautelares.
\end{abstract}

Palabras clave: seguridad, migrantes, derechos humanos, organizaciones civiles, defensores.

\section{Summary}

The impact of migration and security policies implemented by the Mexican State on the human rights of migrants and their defenders is explored. Support is gained from information yielded by the focus groups exercises carried out with members of Civil Organizations (COs) during 2010 and 2011 (1), both in documents of the COs themselves, or in interviews carried out with their most prominent leaders.

1 Dr. en Ciencias Sociales, Investigador y Docente del Instituto de Investigaciones SocialesdelaUniversidadAutónomadeBajaCalifornia.Email:jmoreno@uabc.edu.mx 2 Dra. en Ciencias Sociales, Investigadora y Docente del Instituto de Investigaciones Sociales de la Universidad Autónoma de Baja California. Email: Inino@uabc.edu.mx 
Políticas de seguridad y migración del Estado mexicano: Impacto en derechos humanos de migrantes y sus defensores - José Ascención Moreno Mena y Lya Margarita Niño Contreras

\begin{abstract}
We found that in the government's security strategy a human security approach is absent, whereby such lack has resulted in various human rights violations and the criminalization of migrants and their advocates; it has also lead to the existence of fractures that hinder the performance of such policies, and to the proliferation of players that stress the vulnerability of the players subject matter herein: 63 human rights defenders have been slain, and the Inter-American Human Rights System has issued 158 precautionary measures.
\end{abstract}

Key words: security, migrants, human rights, civil organizations, defenders.

\title{
Introducción
}

El tema de la seguridad en relación con la migración ha sido poco abordado por los estudios académicos en la región ${ }^{3}$; en este sentido, uno de los primeros trabajos en relacionar ambas temáticas fue el de la Fundación Rafael Preciado Hernández (Aviña, 2011) acerca de la incorporación del tema migratorio en la agenda de seguridad. Asimismo, en El Colegio de la frontera norte se han desarrollado investigaciones que tratan de vincular las políticas de seguridad y los derechos humanos de los migrantes nacionales y extranjeros en territorio mexicano (Ramos, 2011); de la misma manera, el Colectivo de análisis de la seguridad con democracia (Casede) ha promovido un debate en torno a las políticas de seguridad y su relación con la migración, resultando de ello algunas publicaciones sobre el tema (Armijo, 2011); finalmente, algunos autores también han abordado el tema pero enfocados a las repercusiones del ataque terrorista del 11 de septiembre de 2001 (Artola, 2005; Calleros, 2010).

El presente trabajo se inscribe en la discusión sobre seguridad, migración y derechos humanos y retoma la perspectiva de las teorías de las relaciones internacionales del Realismo Político (Waltz, 1988) y del Constructivismo de los sociólogos Buzan, Waever y de Wilde (1998) que nos ayudan a explicar cómo la vin-

3 Cabe aclarar que este trabajo forma parte del Proyecto de Investigación $\mathrm{N}^{\circ} 084046$, CB-2007-01 Fondo SEP-CONACYT. 
culación de las políticas de seguridad nacional con temas de la agenda pública, en este caso la migración, pueden llegar a afectar los derechos humanos.

La pregunta general que guía el texto es: ¿cuáles son los factores de la política de seguridad del Estado mexicano que han propiciado mayor vulnerabilidad de la población migrante en los últimos años?

En ese sentido, el objetivo del análisis será identificar a los factores principales que desencadenaron mayor vulnerabilidad de las personas migrantes en territorio mexicano.

La hipótesis de trabajo reside en argumentar que la creciente vulnerabilidad de los migrantes en México, ha sido producto de la política de control de flujos y de la ausencia de una eficaz política de protección gubernamental mexicana hacia los migrantes, en la estrategia que desarrolla el gobierno de México contra el crimen organizado. La securitizacion de la migración y la ausencia de un enfoque de seguridad humana, donde el centro de protección debería ser el individuo que se encuentra en el territorio y bajo la jurisdicción del Estado, ha permitido que proliferen distintas violaciones a los derechos humanos.

Se sostiene que el entorno de inseguridad y violencia que vive el país, también ha vuelto más vulnerables a los defensores de migrantes al convertir esa actividad en un gran riesgo.

El estudio se basa en algunos ejercicios de grupos focales realizados por El Colegio de la frontera norte con miembros de organizaciones civiles de apoyo a los migrantes en los años 2010 y 2011, ${ }^{4}$ entrevistas a los líderes de los grupos, así como en documentos producidos por las propias organizaciones civiles.

4 Los talleres se realizaron para el proyecto "Las políticas de seguridad en México y la vulnerabilidad a migrantes: impactos y recomendaciones", de El Colegio de la frontera norte, financiado por la fundación Ford. 
Políticas de seguridad y migración del Estado mexicano: Impacto en derechos humanos de migrantes y sus defensores - José Ascención Moreno Mena y Lya Margarita Niño Contreras

El texto está estructurado en cuatro apartados. El primero de ellos trata sobre la política de seguridad y política migratoria del gobierno mexicano. En el segundo, se describe la política de seguridad del gobierno de Calderón; en el tercero, se analizan los riesgos que corren los migrantes y sus defensores; finalmente se presentan algunas conclusiones.

\section{Política de seguridad y política migratoria del gobierno mexicano}

Desde la perspectiva de las organizaciones civiles en el 2001 el Estado mexicano definió una política migratoria con un enfoque policial e inquisitorio orientado al control de flujos y no a la protección de las personas migrantes. Esto por la presión del gobierno estadunidense luego del ataque terrorista a las torres de Nueva York ${ }^{5}$. La política de seguridad fue evolucionando hacia un modelo militarista con el gobierno de Calderón. Entonces se fue institucionalizando la securitizacion de la migración y actualmente forma parte del discurso de la seguridad nacional. Ante el clima de violencia e inseguridad que encontró Calderón durante su ascenso a la presidencia de la república, el ejecutivo federal optó por una estrategia basada en el uso de la fuerza y enfocada hacia la militarización. El presidente decidió emplear las instituciones de seguridad pública para llevar adelante una 'guerra' contra organizaciones delictivas que ostentaban cada vez mayor poder en el país. Pero fue más allá, asignó al Ejército un rol central en su estrategia de seguridad pública, que se enfocó principalmente en enfrentar a los cárteles mediante el uso de la fuerza.

5 En esos años el gobierno mexicano se incorporó al Grupo de alto nivel de seguridad fronteriza México-Guatemala y México-Belice (nombrado en el 2002 GANSEF y renombrado GANSEG en el 2008) donde se establecieron convenios entre México y los dos países de la frontera Sur. 
El presupuesto en ese rubro creció de manera desproporcionada, en el 2001 se erogaron para seguridad 7 mil 245 millones de pesos mientras que en el 2011 se aprobaron 135,663.2 millones de pesos a ejecutarse en el 2012 (Avelar, 2011). En el 2007, Calderón abandonó el concepto de "guerra" sustituyéndolo por Estrategia de Seguridad Nacional, y dividió su proyecto en tres puntos fundamentales: 1.-contención y debilitamiento de organizaciones criminales; 2.- fortalecimiento y reconstrucción de las instituciones de seguridad y justicia; y 3.- restitución del tejido social y prevención del delito (Felipe Calderón rinde su informe regional en Mérida, 2011).

En la agenda de la política de seguridad nacional del gobierno de Calderón, se incluyó el tema de la migración y con ello se consolidó la visión de securitización. Se creó el Plan Sur para direccionar la política de migración y se optó por un aumento en la capacidad de vigilancia, control, inspección y contención de los flujos migratorios en todo el corredor de la frontera sur ${ }^{6}$. Se incluyó también la participación del Centro de Investigación y Seguridad Nacional (CISEN) que, a partir de entonces, quedó involucrado en la práctica de la administración de la migración y del asilo en México.

En el Plan Nacional de Desarrollo 2001-2006 se destacó la importancia que tenían los flujos migratorios y la incapacidad para controlar los distintos puntos de internación en el país. En el 2004 se desarrollan convenios de vigilancia y consulta binacional con autoridades de Estados Unidos, tales como el programa OASSIS (Operation vs Smugglers Initiative Safety and Security, por sus siglas en inglés). En mayo de 2005, se publicó en el Diario Oficial de la Federación el Acuerdo en el que el Consejo de Seguridad reconoce al Instituto Nacional de Migración (INM) como Instancia de Seguridad Nacional, y se establece su colaboración con el CISEN (Informe al Relator, 2011).

6 Desde el Istmo de Tehuantepec, el golfo de México y la costa del Pacífico, hasta los estados limítrofes con Guatemala y Belice. 
Políticas de seguridad y migración del Estado mexicano: Impacto en derechos humanos de migrantes y sus defensores - José Ascención Moreno Mena y Lya Margarita Niño Contreras

En el 2007 se explicita la visión de securitización con la integración del dúo migración-seguridad nacional en el Plan Nacional de Desarrollo 2007-2012. Y en el mismo año se firma la Iniciativa Mérida que permitió la entrega de tecnología biométrica por parte de Estados Unidos al INM para el control de las fronteras. En el Programa Nacional de Seguridad del 2009, se menciona explícitamente como una amenaza a la delincuencia organizada, los grupos armados, el narcotráfico, el terrorismo y la vulnerabilidad en las fronteras. En el caso de esta última, "la amenaza consiste en el debilitamiento de los controles institucionales para el ejercicio de la soberanía en las fronteras. Las dinámicas migratorias se identifican explícitamente como un riesgo para la seguridad nacional" (Informe al Relator, 2011:20). En el 2011 con la promulgación de la Ley de Migración se mantuvo el tema de la migración como parte de la seguridad nacional.

\section{La política de seguridad del gobierno de Calderón volvió más vulnerables a los migrantes}

La política de combate al crimen organizado desarrollado por el gobierno federal durante la gestión de Felipe Calderón, ha propiciado mayor vulnerabilidad y criminalización de la población migrante. Ahora las personas migrantes tienen nuevas dificultades que sortear para cruzar hacia Estados Unidos y muchos de esos obstáculos están relacionados con la presencia de las autoridades de todo tipo, a las cuales buscan evitar, y del crimen organizado, que controla buena parte de las rutas por donde cruzan. Eso acrecienta la situación de irregularidad y obliga a los migrantes a la búsqueda de rutas alternas que los colocan en condiciones de mayor vulnerabilidad pues la gran mayoría coincide con los espacios controlados por los cárteles de narcotraficantes. El gobierno mexicano no tiene una estrategia de protección de los migrantes que transitan por esas zonas.

El recrudecimiento de las actividades ilícitas de los grupos delictivos ligados con los cárteles del narcotráfico, aunado con 
la estrategia de seguridad del Presidente Calderón de combatir por medios militares a la delincuencia organizada, ha generado que las regiones por las que transitan las personas migrantes se encuentren en niveles de extrema violencia e inseguridad. Al respecto, Human Rigths Watch (HRW) declara..."en vez de fortalecer la seguridad pública en México, la 'guerra' desplegada por Calderón ha conseguido exacerbar un clima de violencia, descontrol y temor en muchas partes del país" (HRW, 2011:5).

La gran mayoría de las regiones por las que transita el ferrocarril mexicano, medio de transporte más utilizado por las personas migrantes, al que se le conoce como la "bestia", se han convertido en territorios controlados por la delincuencia organizada que en muchas ocasiones operan sus actividades en complicidad con las autoridades municipales, estatales y federales. Ante esto las personas migrantes centroamericanas ahora representan una fuente más de ingreso y ante su calidad de extranjeras sin autorización, se incrementa su condición de vulnerabilidad, siendo víctimas de todo tipo de agresiones y violaciones a sus derechos humanos.

También se han incrementado las agresiones que las personas migrantes mexicanas sufren en las diferentes localidades y municipios de la ruta migratoria, y que son cometidas tanto por autoridades como por grupos delictivos vinculados al narcotráfico. “...los migrantes nunca han sido más vulnerables como ahora, al punto que hoy en día también sufren en carne propia la violencia que impera en la frontera en la medida en que el tráfico de drogas se mezcla con el tráfico ilícito de migrantes y la trata de personas" (Coalición Pro Defensa del Migrante 2009:1).

Las organizaciones civiles (en adelante OC) consideran que el modelo militarista que ha seguido el gobierno federal para combatir el crimen organizado y el narcotráfico se ha equiparado con la visión estadounidense que pone en el mismo tenor al terrorismo, narcotráfico y migración, ya que en los operativos y acciones de seguridad en las fronteras se entremezclan acciones 
Políticas de seguridad y migración del Estado mexicano: Impacto en derechos humanos de migrantes y sus defensores - José Ascención Moreno Mena y Lya Margarita Niño Contreras

de seguridad nacional y seguridad pública, es decir no se hace distinción entre los fenómenos de crimen organizado, trata y migración.

El argumento fundamental del Estado mexicano es que pueden representar un riesgo para la seguridad nacional. Sin embargo, desde la perspectiva de las OC, no se han definido claramente cuáles son esos riesgos, ni tampoco las estrategias o mecanismos para hacerles frente. Ese vacío ha propiciado un tratamiento donde está ausente el enfoque de seguridad humana, facilitando las violaciones a los derechos humanos.

A pesar de que la criminalización de la inmigración clandestina ya fue erradicada de los marcos normativos en el país, de facto se sigue criminalizando a los migrantes, lo que se ve reflejado incluso en los discursos de autoridades policiacas y militares.

Las OC consideran que la política de seguridad nacional que implementa el gobierno mexicano lleva implícita la idea de que se renuncie a ciertos derechos de la ciudadanía en aras de la seguridad nacional, como lo hace el gobierno estadounidense. $Y$ presentan el ejemplo específico de los migrantes extranjeros, en el cual el argumento fundamental que tiene el Estado para garantizar el cese a las violaciones a los derechos humanos de los migrantes y mitigar su sufrimiento, es implementando una política de aseguramiento y detención eficaz.

Es decir, resulta preferible mantener detenidos a los migrantes y repatriarlos a sus países, para evitar que sean vejados, en ese sentido la política de seguridad invisibiliza las violaciones a los derechos humanos. Al igual que las $\mathrm{OC}$ consideramos que no se debe violentar la seguridad humana con el pretexto de preservar la seguridad nacional. No se pueden desconocer de facto los derechos fundamentales de las personas, y mucho menos eludir su obligación de protegerlos. 


\section{Las fisuras de la política de seguridad de Calderón}

Desde su inicio, la política de seguridad del gobierno de Calderón en su relación con la migración se desarrolló con una serie de fisuras y debilidades que no han sido resueltas en la actualidad. La primera fisura tiene que ver con la corrupción de las instituciones encargadas de regular a los migrantes. El reclamo más fuerte ha sido la actuación de los funcionarios del INM en casos de abusos, trata y contubernio con secuestradores. Los datos de la propia Comisión Nacional de Derechos Humanos (CNDH) son contundentes, del periodo 2006 a la segunda mitad del 2011, esa institución abrió 2 mil 129 expedientes por quejas de violaciones a derechos humanos del personal del INM, y en ocho meses -agosto de 2010 - abril de 2011- el INM destituyó a 200 de sus funcionarios, de los cuales 40 quedaron sujetos a proceso penal (Blancas, 2011).

Figura 1. Debilidades y fisuras de la estrategia de seguridad federal

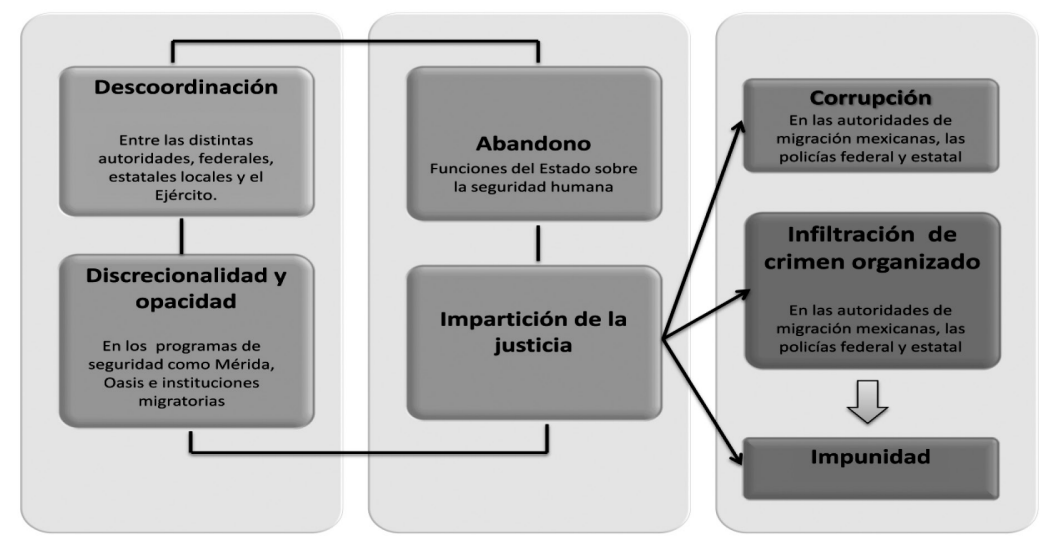

Fuente: elaboración propia

Las noticias sobre participación de agentes del INM en casos de corrupción, abusos y complicidad con miembros del crimen son frecuentes como se puede apreciar en los encabezados de algunos medios: "Detienen a 2 agentes de migración por abusos. 
Políticas de seguridad y migración del Estado mexicano: Impacto en derechos humanos de migrantes y sus defensores - José Ascención Moreno Mena y Lya Margarita Niño Contreras

Se les acusa por presuntamente haber prostituido a dos mujeres inmigrantes centroamericanas en el estado de Chiapas, en el sur de México" (AP, 2011). "Caen agentes del INM por secuestro de migrantes. La Procuraduría General de la República investiga a seis agentes del Instituto Nacional de Migración (INM) por su relación con el secuestro de migrantes" (González, y Mejía, 2011). Migrantes acusan a INM de entregarlos a criminales. "El Instituto Federal de Defensoría Pública informó que 120 migrantes que fueron rescatados, reconocieron a oficiales del instituto como las personas que los bajaron del camión y los entregaron a hombres armados" (González, 2011).

Las declaraciones del propio presidente parecen confirmar los reclamos de las organizaciones civiles, Calderón al referirse a los agentes del INM menciona: "Es inadmisible que participen en la violación a derechos humanos o que se coludan con delincuentes. (...) El gobierno federal ha iniciado un profundo proceso de depuración de las filas del instituto" (CNN, 2011).

En los talleres realizados por el Colegio de la Frontera Norte con las OC, las policías municipales fueron señaladas como las más deshonestas y corruptas, por sus acciones de extorsión, robo y actitudes discriminatorias. En Tijuana las consideran como el enemigo público número uno de los migrantes. En segundo lugar se menciona a los agentes federales, que al igual que las policías municipales y ministeriales, actúan en contubernio y complicidad con el crimen organizado apoyándolo en las actividades delictivas (Colef, 20011). Estos actores tienen vínculos con las bandas de "asalta migrantes" y secuestradores en las localidades donde se da la mayor afluencia de migrantes, tal es el caso de Altar, Sonora y las montañas de Tecate.

De esta manera, son los propios uniformados -que deberían proteger la integridad de los migrantes- quienes les avisan a los secuestradores sobre la presencia de centroamericanos, y en algunas ocasiones son ellos mismos quienes los llevan en sus patrullas hasta las casas de seguridad. En menor medida se menciona 
a los grupos Beta, especialmente a los que trabajan en la frontera norte, los cuales son señalados como cómplices de las bandas delictivas, de los "polleros" o "coyotes"7. Finalmente, también están los agentes aduaneros, que se dedican a quitarles el poco dinero que traen luego de ser expulsados de Estados Unidos. Lo anterior es reconocido en el informe que presentó el Relator especial de la ONU sobre los derechos humanos de los migrantes cuando se refiere a:

[...] la omnipresencia de la corrupción en todos los niveles del gobierno y la estrecha relación de numerosas autoridades con las redes de bandas, la extorsión, las violaciones y las agresiones contra los migrantes continúan. Los migrantes de Guatemala, El Salvador, Honduras y Nicaragua parecen constituir la mayoría de las víctimas (Bustamante, 2009). En términos generales, la corrupción incrementa las condiciones de vulnerabilidad de las personas migrantes.

La segunda fisura es la infiltración del crimen organizado en los mandos policiacos de todos los niveles. Vínculo que facilita la extorsión de las familias y los migrantes secuestrados. Por esa razón, según las OC, las denuncias no prosperan. Resulta interesante la aseveración de uno de los defensores de migrantes, de que la migración ha quedado atrapada entre el crimen organizado y las medidas institucionales de seguridad (Pantoja, 2009).

\footnotetext{
7 Se conocen como coyotes y/o polleros a los traficantes de migrantes, que se presentan como expertos en cruzar la frontera sin permiso y de forma clandestina (smugglers en la terminología de los Estados Unidos). Dichas expresiones se encuentran normalizadas en el habla cotidiana de millones de hispano-parlantes y aparecen desde principios del siglo XX en la literatura mexicana y en los estudios de migración, según lo explica Guillermo Alonso (2010). Los coyotes y / o polleros se hicieron populares durante el programa de Braceros entre 1942 y 1964, donde México aportó mano de obra para el sector agrícola y ferroviario a la economía de Estados Unidos. El convenio permitió la entrada de trabajadores mexicanos de manera legal a la unión americana pero al mismo tiempo se desarrolló un flujo clandestino de personas que se apoyó en los coyotes y/o polleros. Esto ha continuado hasta nuestros días.
} 
Políticas de seguridad y migración del Estado mexicano: Impacto en derechos humanos de migrantes y sus defensores - José Ascención Moreno Mena y Lya Margarita Niño Contreras

Los reportes de los medios en los gobiernos locales son elocuentes, por ejemplo en Veracruz, "Despidos de policías en Boca del Río por infiltración de crimen: Acosta" (lainformacion.mx, 2011), o bien en Nuevo León. “El ex titular de Seguridad del estado confirma la relación entre funcionarios y el narcotráfico, como reveló WikiLeaks" (Estrada, 2011). El propio presidente Calderón reconoce la infiltración del crimen en los mandos policiacos, en una gira por Durango declaró a los medios:

Renovar, depurar y limpiar las policías. Porque lo peor que le puede pasar a una comunidad, y eso por desgracia le ha pasado a varias comunidades en el país incluyendo a varias de Durango, es que sean las propias autoridades policiacas las que estén coludidas con los criminales, porque es como poner precisamente al zorro o al coyote a cuidar el corral de las gallinas. (Informador.com, 2012).

La tercera fisura de la política de seguridad en relación con la migración es el alto grado de impunidad con que se manejan las autoridades y los ministerios públicos. Al respecto, Acosta (2001:2) la define como "la ausencia de castigo para un delito que se comete". Continuando con Acosta: La falta en su conjunto de investigación, persecución, captura, enjuiciamiento y condena de los responsables de delitos, produce impunidad. A su vez, la impunidad propicia la repetición crónica de los hechos delictivos y somete a las víctimas a un estado de indefensión. Esta impunidad, aunada a un aumento significativo de la criminalidad y de violaciones graves a los derechos humanos en los últimos años, acentúa la inseguridad en un círculo vicioso que no parece tener fin. Afecta sobre todo a poblaciones con mayor posibilidad de encontrarse en situaciones de vulnerabilidad; tal es el caso de las mujeres, las niñas y los migrantes, como lo hemos atestiguado recientemente.

La cuarta fisura es la discrecionalidad y la opacidad en los programas de seguridad y especialmente en las instancias que tienen que ver con la regulación migratoria. A fines del 2011 la organización Fundar, Centro de Análisis e Investigación A.C. 
sostenía que la información presupuestaria del INM no permitía identificar cuántos recursos se habían canalizado para proteger a los migrantes e implementar una política de control del Estado. Rodolfo Córdova, uno de los investigadores de esa organización, mencionaba que:

La falta de claridad en la información presupuestaria no deja espacio para que se evalúe y mejore la gestión pública en esta materia. Más aún, la imposibilidad de conocer de manera desagregada el presupuesto del INM debilita la transparencia y la rendición de cuentas del INM (Saúl, 2011:9).

A raíz de esa situación la OC Fundar se dio a la tarea de desarrollar un trabajo de incidencia logrando que el INM se vea obligado a informar a la Cámara de Diputados, a través de informes trimestrales de carácter público, sobre cuántos recursos se destinan a cada uno de los cuatro programas de protección a migrantes que implementa, Grupos Beta de Protección a Migrantes, Repatriación Humana, Oficiales de Protección a la Infancia (OPIS) y Programa Paisano (Fundar, 2011) . $^{8}$

La quinta fisura es tal vez el punto más importante, la estrategia de seguridad no contempló la seguridad humana y la protección de las personas que saldrían afectadas. Las OC sostienen que el Estado mexicano ha abandonado sus funciones de seguridad ciudadana y que sigue prevaleciendo la falsa visión de que las casas de migrantes pueden ser guaridas de criminales. En eso coinciden también algunas organizaciones internacionales, al respecto en el Informe 2010 de la Oficina del Alto Comisionado de las Naciones Unidas para los Derechos Humanos en México se menciona:

8 De acuerdo con el Art. 60 del Decreto de presupuesto de egresos de la federación para el ejercicio fiscal 2012, el INM deberá informar a la Cámara de Diputados cuántos recursos destina a sus programas de protección, lo cual es un avance en la demanda de transparencia de los programas públicos. 
Políticas de seguridad y migración del Estado mexicano: Impacto en derechos humanos de migrantes y sus defensores - José Ascención Moreno Mena y Lya Margarita Niño Contreras

El incremento de la violencia relacionada con el crimen organizado ha intensificado la vulnerabilidad de las y los defensores. La ausencia de un enfoque de derechos humanos en el diseño e implementación de algunas políticas de seguridad puede llegar a ocasionar restricciones de derechos indispensables para que las y los defensores ejerzan su labor (OACDHONU, 2010:11).

Desde las OC se consideró que el presidente debió adoptar las medidas necesarias para reformar y fortalecer las instituciones de seguridad pública del país con un programa de depuración, capacitación, profesionalización y coordinación para hacerlas más eficientes antes de iniciar una "guerra" contra el crimen organizado. Cosa que apenas comenzó a llevar a cabo después de la matanza de los 72 migrantes en San Fernando, Tamaulipas, el pasado 2010 .

Con las acciones y los programas de seguridad implementados por el gobierno federal, las OC consideran que se ha institucionalizado la violencia contra los migrantes porque se falta al debido proceso, cerrándose las opciones para su protección y seguridad. Incluso se han incrementado los riesgos para los ciudadanos de las localidades fronterizas, al ponerlos entre dos fuegos, cuando se realizan operativos para detener criminales.

Las organizaciones de la sociedad civil también critican los operativos que realizan los agentes del INM en los trenes que van del suroeste hacia el centro y norte del país; en primer lugar, sostienen que dichas acciones no tienen ningún fundamento legal, y, en segundo lugar, al realizar las persecuciones, provocan accidentes que ponen en riesgo la vida de los migrantes. Por eso, se considera que los operativos violan el mismo marco normativo nacional como la seguridad, integridad y dignidad humana.

Desde la perspectiva de las OC, con el incremento de las medidas de seguridad también han proliferado una serie de actores civiles que si bien ya existían, no eran tan visibles como ahora; por ejemplo, las redes criminales que han emergido en las rutas 
y espacios de la migración, han sometido a los tradicionales "polleros" que tenían cierto "código de ética" en ambas fronteras. Estas bandas han encontrado en el tráfico ilícito de migrantes, la extorsión y el secuestro de migrantes una forma de hacerse de un ingreso fácil por la naturaleza misma del fenómeno: personas sin documentos que ven en los abusos, asaltos y extorsiones, parte del costo implícito del migrante.

Otro de los actores civiles del que hacen referencia las organizaciones de la sociedad civil son los agentes o guardias de seguridad privados contratados para la vigilancia de los trenes, que se han convertido en una verdadera pesadilla para los migrantes centroamericanos. Las organizaciones civiles, Posada del Migrante Belén, Humanidad Sin Fronteras, A.C. y Frontera Con Justicia, A.C. de Coahuila (2009), han denunciado las constantes extorsiones, amenazas y humillaciones que sufren los migrantes centroamericanos por los guardias privados de la compañía de tren que inicia en Tenosique, Tabasco, cruza Coatzacoalcos, Tierra Blanca, Orizaba, Apizaco, Celaya, San Luis Potosí, Saltillo y Monterrey, y llega hasta las fronteras de Piedras Negras, Nuevo Laredo y Matamoros.

Un tercer actor mencionado son los "asalta migrantes" o "bajadores", que encapuchados y con armas largas, asaltan a los migrantes en las veredas y montañas por donde regularmente tienen que cruzar. Estos individuos, además de asaltar y extorsionar, violan a las mujeres que van en los grupos. Se mencionan en la región noroeste en la zona de La Rumorosa, en Baja California, y Altar, en Sonora; en la región noreste en Reynosa y Nuevo Laredo en Tamaulipas; en los municipios de Coatzacoalcos y Tierra Blanca en Veracruz; Tenosique en Tabasco; Ixtepec en Oaxaca, y en varias ciudades de Chiapas. En general, los asaltos cometidos por delincuentes y bandas delictivas ocurren en todas las localidades, ciudades, municipios y estados por los que transitan las personas migrantes y forman parte del riesgo cotidiano que las personas aceptan como uno de los costos que deben asumir al tomar la decisión de migrar. 
Políticas de seguridad y migración del Estado mexicano: Impacto en derechos humanos de migrantes y sus defensores - José Ascención Moreno Mena y Lya Margarita Niño Contreras

Otros nuevos actores son las personas que trabajan en el transporte público como taxistas y conductores de camiones colectivos (las conocidas "combis" en la frontera entre Guatemala y México) que se han convertido en los "enganchadores" por excelencia de los migrantes. Trabajan en contubernio con los "polleros", y son facilitadores para los secuestros, cuando no los entregan directamente en las casas de seguridad. Los taxistas se ubican en las salidas de las garitas en la frontera norte, donde los migrantes son deportados, en las centrales camioneras y en los parques públicos. Al respecto, resulta ilustrativo el comentario de uno de los responsables de los albergues: "Se sabe ahí en la población, que los que tienen el mando son los grupos mafiosos que están en la región, y ellos son los patrones de todos los policías que hay ahí" (Peraza, 2009).

Asimismo, las OC reconocen que los narcotraficantes, en conspiración con las propias autoridades, utilizan a los migrantes como "burros" para transportar droga hacia Estados Unidos. En múltiples ocasiones, las organizaciones de narcotráfico se "asocian" u obligan a las bandas de "polleros" a internar drogas en Estados Unidos, utilizando como vehículo a los propios migrantes. En eso consiste el "derecho de piso" que los "polleros" pagan. Las bandas de "polleros" también están incorporando a menores de dieciocho años/niñas, niños y adolescentes a sus filas, sobre todo porque éstos, al ser detenidos en Estados Unidos y en México, no son sujetos de cargos delictivos.

\section{Los secuestros: reflejo de la incapacidad del gobierno mexicano para garantizar la seguridad de los migrantes}

En el 2009, la Comisión Nacional de los Derechos Humanos (CNDH) presentó el Informe Especial sobre los casos de secuestro en contra de migrantes. En esa ocasión, la CNDH informó que en el periodo comprendido entre septiembre de 2008 y febrero de 2009 , tuvo conocimiento de 9.758 migrantes que fueron privados 
de su libertad. Se documentó que en el sur del país fueron secuestrados el 55\% de las víctimas; en el norte, el 11,8\%; en el centro el 1,2\%; dos años después la CNDH presentó su informe 2011, en el que se registra que durante seis meses del 2010 analizados por esa institución junto con organismos de la sociedad civil, resultaron 11,333 víctimas, $67,4 \%$ de los eventos sucedieron en el sureste, $29,2 \%$ en el norte y 2,2\% en el centro del país (CNDH, 2011).

La CNDH también menciona la complicidad de funcionarios y agentes migratorios en un $8,9 \%$ de los casos de secuestro. Y entre las autoridades identificadas, las más frecuentes son las corporaciones de policías municipales, agentes del Instituto Nacional de Migración e Instituciones de Seguridad pública estatal, así como la Policía Federal (CNDH, 2011).

De igual manera, en el mencionado informe de la $\mathrm{CNDH}$, se identifican los Estados y zonas de mayor riesgo de secuestro para los migrantes, que en el caso de la frontera norte se representan a continuación:

Mapa 1. Zonas de altos riesgos de secuestros de migrantes en la frontera de México

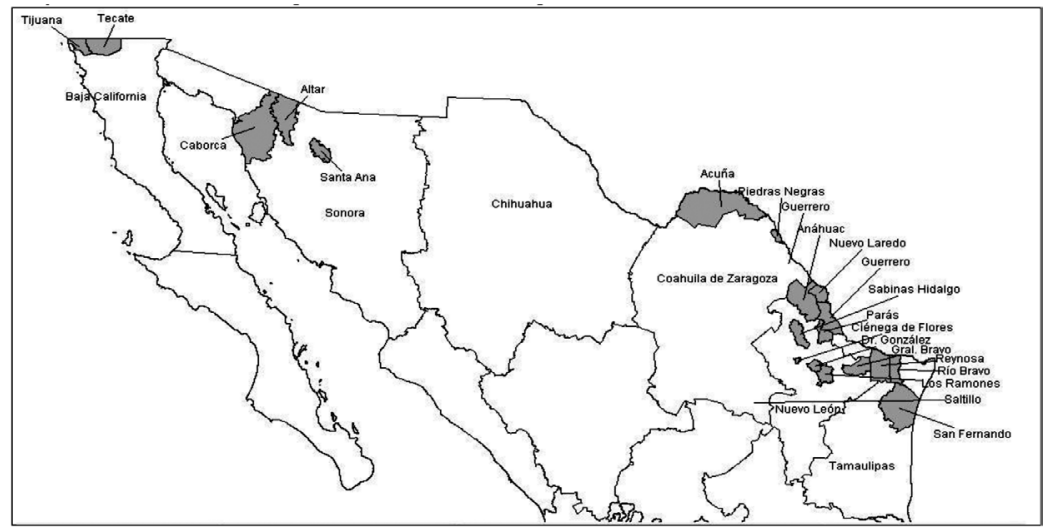

Fuente: Elaborado por José Luis Batiz López, con datos de la CNDH, 20011

El secuestro y asesinato de los 72 migrantes en el municipio de San Fernando, Tamaulipas, en agosto del 2010, puso en la opinión 
Políticas de seguridad y migración del Estado mexicano: Impacto en derechos humanos de migrantes y sus defensores - José Ascención Moreno Mena y Lya Margarita Niño Contreras

pública internacional, el problema de violencia extrema que vivían los migrantes, especialmente centroamericanos. La matanza evidenció la falta de protección del gobierno mexicano hacia la población migrante indocumentada que transita hacia Estados Unidos; también la descoordinación entre los distintos niveles de autoridades para investigar los casos, así como la carencia de una política integral de atención a las víctimas del secuestro sin importar su condición migratoria y que garantice su seguridad e integridad.

El asunto de los secuestros mostró una de las debilidades de la política de seguridad del gobierno mexicano, la carencia de un marco jurídico de protección a los migrantes, de ahí surgió el apresuramiento para la creación de un marco jurídico (Ley Migratoria) acorde con las nuevas situaciones.

El delito de trata de personas es otro de los derivados del secuestro; en el caso de las mujeres secuestradas a menudo éstas son violadas sexualmente y en múltiples ocasiones obligadas a prostituirse. En el caso de los varones, son obligados a trabajar para los secuestradores, especialmente en los sembradíos de droga. Otros deben limpiar las propias casas de seguridad en las que se encuentran, cocinar para los demás migrantes o son utilizados como parte de la servidumbre de los jefes de las bandas delictivas.

En el informe sobre la visita a México presentado por el Relator Especial de la Organización de la Naciones Unidas (ONU) sobre los derechos humanos de los migrantes, se cuestionó que pese a la gravedad de la situación por el creciente índice de secuestros y asesinatos de migrantes, no se ve ningún indicio de mejoría porque no hay compromiso de los gobiernos involucrados para revertirla (ONU, 2009). En el 2010 un grupo de organizaciones presentó en audiencia pública ante la Comisión Interamericana de Derechos Humanos un informe sobre la tragedia humanitaria que representan los secuestros a personas migrantes centroamericanas. Además de reiterar las formas en las que ocurren los secuestros, los lugares en los que se presentan los delitos manifestados, el informe menciona: 
[...] la falta de una respuesta eficaz por parte del Estado mexicano que garantice el acceso a la justicia y la reparación del daño a las personas migrantes víctimas de secuestro y otros actos graves de violencia y violaciones a los derechos humanos; situación que configura una violación continua de las obligaciones de proteger los derechos de las y los migrantes en términos de igualdad (Informe ante CIDH, 2010):

En este sentido las organizaciones reiteran que el Estado mexicano carece de una política integral de atención a las víctimas del secuestro sin importar su condición migratoria y que garantice la seguridad e integridad tanto de las personas migrantes como de las y los defensores de los derechos humanos. También sostienen que no hay verdaderos impactos en la prevención, atención y reparación del daño para los migrantes secuestrados y sus familias en las acciones que realiza el Estado.

Las OC consideran que esas situaciones confirman la incapacidad del gobierno mexicano por mantener un estado de derecho, la violación de los derechos humanos ya sea por comisión u omisión y la falta de voluntad política.

\section{La defensa de los derechos de los migrantes, un gran riesgo}

La inexistencia de un enfoque de derechos humanos en la estrategia de seguridad del gobierno mexicano, aunado con las fisuras de origen, han traído consecuencias colaterales y situaciones no previstas para los defensores de derechos humanos en el país. Líderes de organizaciones civiles, están padeciendo actos de hostigamiento, amenazas del crimen organizado y de funcionarios estatales, violaciones a sus derechos a la vida, la integridad, libertad y seguridad personal relacionadas presuntamente por su actividad de defensa. 
Políticas de seguridad y migración del Estado mexicano: Impacto en derechos humanos de migrantes y sus defensores - José Ascención Moreno Mena y Lya Margarita Niño Contreras

En lo que va del gobierno de Calderón, al menos 63 defensores y luchadores sociales han sido asesinados. Seis de ellos, entre diciembre de 2010 y noviembre de 2011. Entre los autores de los crímenes se mencionan comandos armados, grupos paramilitares, policías y militares (Flores, 2011).

La OACDHONU en la actualización de su informe 2010, dio a conocer que durante el período de septiembre 2009 hasta octubre de 2010 se registraron un total de 37 presuntas agresiones en contra de defensores y defensoras. Ante esta situación de violencia, el sistema interamericano de derechos humanos ha dictado 158 medidas cautelares para más de 200 defensores (Actualización, 2010).

En el caso particular de las organizaciones civiles que atienden las necesidades de las personas migrantes y que promueven y defienden sus derechos, se han vertido distintas denuncias, especialmente de la Dimensión Pastoral de Movilidad Humana', que presentó en julio del 2011 su "Informe sobre la situación de las y los defensores de las personas migrantes en México" (DPMH, 2011).

En el citado informe se menciona que han sido asesinados dos defensores de Derechos Humanos de migrantes; se han registrado 46 incidentes de riesgo entre 2010 y 2011. También el entorno de violencia e inseguridad ha generado el cierre de tres albergues, en San Luis Potosí, Tamaulipas y Chiapas. A lo anterior también se suma el acoso constante contra Fray Tomás González Castillo, Director del Centro de Derechos Humanos del Usumacinta y La 72 Hogar-Refugio para Personas Migrantes en Tenosique, Tabasco. Asimismo, tres centros y su personal gozan de medidas cautelares de la Comisión Interamericana de Derechos Humanos: Albergue Hermanos en el Camino, de Ixtepec,

9 Dimensión de la Movilidad Humana depende de la Pastoral Social de la Conferencia del Episcopado Mexicano (CEM). 
Oaxaca; Belén, Posada del Migrante en Saltillo, Coahuila, y el Centro de Derechos Humanos, de Nuevo Laredo. Por su parte la Comisión Nacional de Derechos Humanos (CNDH), también ha dado medidas cautelares de protección a trece centros. Entre ellos están los tres arriba mencionados, así como Casa del Peregrino, Frontera Digna, en Piedras Negras, Coahuila; Casa de la Calidad Cristiana, en San Luis Potosí, y Albergue San Juan Diego, Lechería, Estado de México. Al respecto se presenta la siguiente gráfica.

\section{Gráfica 1. Incidentes en contra de los defensores de Derechos Humanos}

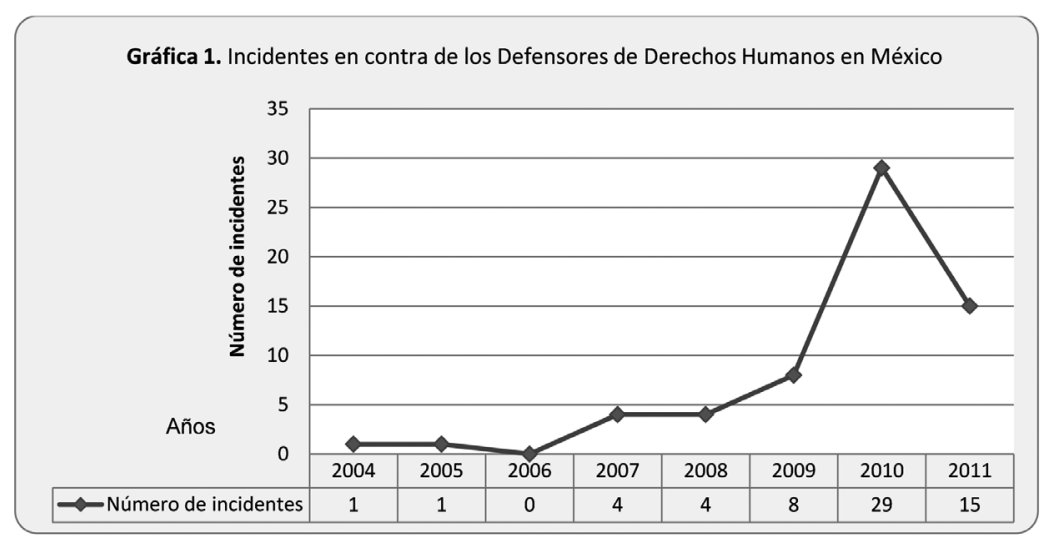

Fuente: Informe sobre la situación de las y los defensores de las personas migrantes en México. (DPMH, 2011, p. 5).

Ante las agresiones a los defensores de migrantes, se ha presentado un éxodo de voluntarios extranjeros en Coahuila. En este mismo sentido; el presidente de la Dimensión de la Movilidad Humana (DPMH), el Arzobispo de Tijuana Rafael Romo Muñoz, sostiene que México se ha convertido en un país de riesgo para el trabajo en favor de los migrantes y para quienes transitan por su territorio en busca de llegar a Estados Unidos (Saldierna, 2011).

El incremento de la violencia, del país y hacia los migrantes, ha intensificado la situación de vulnerabilidad. La impunidad constituye el factor que en mayor medida aumenta el riesgo de los defensores porque los deja en un estado de indefensión y des- 
Políticas de seguridad y migración del Estado mexicano: Impacto en derechos humanos de migrantes y sus defensores - José Ascención Moreno Mena y Lya Margarita Niño Contreras

protección. Las OC sostienen que existe complicidad entre las autoridades y el crimen organizado, y desde nuestro punto de vista son fundadas sus acusaciones. La OACDHONU concuerda con ellas en que "el principal riesgo de los defensores de las personas migrantes se relaciona con la denuncia de las actividades del crimen organizado, porque en ocasiones existe complicidad entre las autoridades y el crimen organizado" (OACDHONU 2010:21). Por su parte, la secretaria ejecutiva de la DPMH, la religiosa Leticia Gutiérrez Valderrama, ha denunciado también los constantes ataques de los que son víctimas los agentes de Pastoral Migratoria (Esqueda, 2011:13).

Los tipos de violaciones que han sufrido los defensores según el informe de la DPMH son: La privación del derecho a la vida y a la libertad; agresiones físicas; atentados contra la integridad; hostigamientos; uso arbitrario del sistema penal; injerencias arbitrarias (robo de información y el allanamiento a oficinas); amenazas; y acciones de deslegitimación del trabajo de los defensores de derechos humanos de las personas migrantes (DPMH, 2011:7).

Los actores de las constantes violaciones son las "Policías de los tres niveles de gobierno; Instituto Nacional de Migración; Poder Legislativo local; delincuencia organizada; delincuencia común; medios de comunicación; población civil sin sensibilizar" (DPMH, 2011:11).

Los defensores de migrantes han tenido que navegar contra los prejuicios que prevalecen en torno a los derechos humanos en México. Existe una criminalización contra los migrantes desde las esferas estatales, lo que genera obstáculos para el trabajo de los defensores. Las acusaciones de que defienden a delincuentes y que sólo protestan y no contribuyen, deslegitiman su trabajo. Un número importante de las organizaciones ha tenido que dejar en un segundo plano temas fundamentales como los de derechos humanos de los migrantes para centrar la atención en su propia seguridad. 
Autoridades locales utilizan a los medios de comunicación para descalificar el trabajo de los defensores y difundir una imagen distorsionada de las causas que los motivan, y provocan daños a la imagen personal y aumento a su situación de vulnerabilidad, pero lo que es peor, inducen a que la ciudadanía deje de identificarse con el trabajo de defensa de derechos humanos y se restrinja el nivel de solidaridad, provocando sentimientos contra los migrantes y los albergues, como en los casos del refugio Hermanos en el Camino en Ixtepec, Oaxaca y San Juan Diego, lechería del Estado de México, donde se presentan reacciones hostiles provenientes de las comunidades (OACDHONU, 2010:21).

En Coahuila, el Congreso Estatal ha estado haciendo llamados a la federación para que se realicen reformas a la Ley General de Población con el fin de regular el funcionamiento de las casas del migrante, con el argumento de que ahí se albergan personas con antecedentes penales o de perfil criminal, y se evita la intervención de las autoridades. Prácticamente están criminalizando la labor de los defensores.

Las descalificaciones también vienen de las autoridades que se encuentran dentro de la estrategia de seguridad, las declaraciones del secretario de Marina, Mariano Francisco Saynez, donde acusa a las OC de ser utilizadas por grupos delictivos para obstruir la labor de los militares o bien del INM, que en dos ocasiones ha tratado de involucrar al Padre Solalinde en el delito de trata y de abandono de migrantes.

\section{Conclusiones}

Garantizar el respeto a los derechos humanos de todo individuo que se encuentre en territorio nacional debe ser una primicia del gobierno mexicano, sin embargo, en la política que involucra a la de seguridad y migración implementada por el gobierno de Calderón, se optó por una visión de securitización caracterizada por tener grandes debilidades como lo es la falta de seguridad 
Políticas de seguridad y migración del Estado mexicano: Impacto en derechos humanos de migrantes y sus defensores - José Ascención Moreno Mena y Lya Margarita Niño Contreras

humana. Lo anterior ha conllevado a la proliferación de distintas violaciones a los derechos humanos, incrementando la vulnerabilidad de los migrantes y sus defensores como nunca antes en la historia de la migración en México.

A escasos días de haberse llevado a cabo las elecciones en México, podríamos decir que la nueva administración tiene principalmente dos retos ineludibles: el primero de ellos es circunscribirse a los tratados internacionales firmados en materia de derechos humanos y el segundo consiste en impulsar y aplicar la nueva Ley de Migración firmada en mayo del presente año, actualmente estancada.

\section{Bibliografía}

\section{Libros o documentos teóricos-conceptuales y metodológicos}

Acosta, Mariclaire (2011, Agosto). "Superar la impunidad", reporte de investigación, CIDE/financiado por la fundación Ford, recuperado el día 15 marzo del 2012 de: http:/ / es.scribd. com/doc/64415702/Superar-la-impunidad-hacia-unaestrategia-para-asegurar-el-acceso-a-la-justicia-en-MexicoMariclaire-Acosta-coordinadora

Belén,Posada delMigrante,HumanidadSinFronteras,A.C.,FronteraCon Justicia (2009, mayo). “Quinto Informe Sobre la Situación de los Derechos Humanos de las Personas Migrantes en Tránsito por México". Saltillo, Coahuila, en línea: http:/ / www. sinfronteras.org. $\mathrm{mx} / \mathrm{attachments/article/288/DOCU-}$ MENTO_INFORME_MIGRANTES_EN_TRANSITO.pdf

Bustamante, Jorge (2009). "Informe del Relator Especial de Naciones Unidas sobre los Derechos Humanos de los Migrantes sobre su visita a México realizada del 9 al 15 de marzo de 2008", Doc. A/HRC/11/7/Add.2, (24 de marzo de 2009), párrafo 65, en línea: http:/ / daccess-dds-ny.un.org/doc/UNDOC/ GEN/G09/125/76/PDF/G0912576.pdf?OpenElement

Coalición Pro Defensa del Migrante, Boletín informativo, 30 de septiembre del 2009. 
Comisión Nacional de los Derechos Humanos (2009): “Informe Especial de los Casos de Secuestro en Contra de Migrantes, México". En línea: http:/ / www.cndh.org.mx/node/3

(2011). "Secuestros a personas migrantes centroamericanas en su tránsito por México", entregado y presentado ante la Comisión Interamericana de Derechos Humanos en su 138 periodo de sesiones, en línea: http:/ / www.cndh.org.mx/ sites/all/fuentes/documentos/Index/InfEspecialSecuestroMigrantes_8

Dimensión pastoral de la movilidad humana DPMH (2011): “Defensoras y Defensores de las Personas Migrantes en México" en línea: Saltillo, Coahuila. Recuperado el 12 de febrero del 2012, de http://www.diocesisdesaltillo.org.mx/descargas/defensoras_defensores.pdf

El Colegio de la Frontera Norte (2011): Talleres “Las políticas de seguridad en México y la vulnerabilidad de los Migrantes: impactos y recomendaciones “. Financiado por la Fundación Ford.

Human Rights Watch (2011, 9 de noviembre): "Ni seguridad, ni derechos. Ejecuciones, desapariciones y Tortura en la guerra contra el narcotráfico en México", Informe 2011, en línea: http:/ / www.hrw.org/es/reports/2011/11/09/ni-seguridad-ni-derechos-0

Informe al Relator Especial de Trabajadores Migratorios y Miembros de sus Familias de la Comisión de la CIDH (2011). Oficina del alto comisionado de las Naciones Unidas de los Derechos Humanos en México. OACDHONO (2010): “Defender los derechos humanos: entre el compromiso y el riesgo". Informe sobre la situación de las y los defensores de derechos humanos en México, en línea: http://www.hchr.org.mx/ index.php/publicaciones-y-documentos / 248-actualizacion-2010 informes

Pantoja, Pedro (2009): "Políticas de Migración y de Seguridad en México: Marco Institucional, Implementación y recomendaciones". 1er Taller y sesión de diálogo, El Colegio de la Frontera Norte, Tijuana, Baja California, 21 de agosto de 2009. Moreno Mena. "entrevista personal”.

Peraza, Prisciliano. (2009): "Políticas de Migración y de Seguridad en México: Marco Institucional, Implementación y recomendaciones". 1er taller de sesión y diálogo, El Colegio de la 
Políticas de seguridad y migración del Estado mexicano: Impacto en derechos humanos de migrantes y sus defensores - José Ascención Moreno Mena y Lya Margarita Niño Contreras

Frontera Norte, Tijuana, Baja California, 21 de agosto de 2009. Moreno Mena, "entrevista personal".

\section{Medios de comunicación masivos}

Alís, Krupskaia (2011, 24 de mayo). “Felipe Calderón promulga ley que garantiza la protección de los migrantes". CNN México, en línea: recuperado el día 20 de febrero de 2012, de http://mexico.cnn.com/ nacional / 2011/05/24/felipe-calderon-promulgaley-que-garantiza-la-proteccion-de-los-migrantes

AP (2011,18 de mayo): "Detienen a 2 agentes de migraciones por abusos". El mexicano, en línea: recuperado el día 20 de febrero del 2012, de http://www.elmexicano.com.mx/ informacion/noticias/1/2/nacional/2011/05/18/473946/ detienen-a-2-agentes-de-migraciones-por-abusos.aspx

Avelar, Bautista Daniel (2011): Columna política "Desde el Fondo", Presupuesto para el 2012, Seguridad y defensa de periodistas, en línea: http://www.tamaulipasaldia.com. $\mathrm{mx} / \mathrm{cms} /$ opinion /50-daniela-avelar-bautista / 2184presupuesto-para-el-2012-seguridad-y-defensa-deperiodistas.html

“Despidos de policías en Boca del Río por infiltración de crimen: Acosta" (2011, 21 de diciembre): lainformacion.mx, en línea: recuperado el día 28 de febrero del 2012 de http:/ / noticias. lainformacion.mx/policia-y-justicia / criminalidad / despidos-de-policias-en-boca-del-rio-por-infiltracion-decrimen-acosta_ASR89TqZkwLw5MKzXzjO2/

Esqueda, Ernesto (2011, octubre): “La iglesia de México pide que se denuncien los abusos a inmigrantes". Jóvenes Sin Fronteras, Revista de misioneros de San Carlos, Scalabrinianos, N0. 32, 12-13en línea: Recuperado el 20 de marzo del 2012, de, http: / / www.jsf.com.mx/verconId.php?id=01485\&tipo=2

Estrada, Javier (2011, 16 de febrero): “Cables, infiltraciones y violencia: el declive policial de Nuevo León". CNN México, en línea: Recuperado el día 23 de febrero de 2012, de http:/ / mexico.cnn.com/nacional/2011/02/16/cables-infiltraciones-yviolencia-el-declive-policial-de-nuevo-leon

"Felipe Calderón rinde su informe regional en Mérida" (2011, 10 de septiembre): La revista peninsular, en línea: Recuperado 
el día 10 de febrero del 2012, de http://www.larevista. com.mx/noticias/felipe-calderon-rinde-informe-regionalmerida-34660/

Flores, Nancy (2011, 7 de diciembre): “63 Defensores de derechos humanos asesinados". Revista Contralínea, Nº 262, en línea: Recuperadoel día 12 deenero del2012, dehttp: / / contralinea. info/archivo-revista /index.php / 2011/12/07 / 63defensores-de-dh-asesinados /

Fundar centro de análisis e investigación en línea: de http:/ / fundar.org. $\mathrm{mx} / \mathrm{mexico} /$ ?page_id $=235$

González, María de la Luz (2011, 9 de mayo): “Migrantes acusan a INM de entregarlos a criminales". El Universal .mx, en línea: Recuperado el día 10 de enero del 2012 de http:/ / www. eluniversal.com.mx/notas/764295.html

y José Mejía (2011, 10 de mayo): “Caen agentes del INM por secuestro de migrantes". El Universal.mx, en línea: Recuperado el día 10 de enero del 2012 de http:// www.elmexicano.com.mx/informacion/noticias/1/2/ nacional/2011/05/18/473946/detienen-a-2-agentes-demigraciones-por-abusos.aspx

"Infiltración policial es como dejar que el coyote cuide el gallinero: Presidente" (2012, 1 de marzo): informador.com.mx, en línea: Recuperado el día 10 de marzo del 2012 de http: / / www.informador.com.mx/mexico/2012/360094/6/ infiltracion-policial-es-como-dejar-que-el-coyote-cuide-elgallinero-presidente.htm

Saldierna, Georgina (2011, 23 de julio): “Funcionarios buscan intimidar a los defensores de migrantes". La Jornada, pp. 27.

Saúl, Lilia (2011, 9 de noviembre): "Denuncian opacidad en presupuesto de INM". El Universal, en línea: http:/ / www.eluniversal. com.mx/notas/807624.htm 